\title{
EXTRACCIÓN DE PECTINA DE RESIDUOS DE CÁSCARA DE NARANJA POR HIDRÓLISIS ÁCIDA ASISTIDA POR MICROONDAS (HMO)
}

\section{Vanesa Y. Zegada Franco}

\section{RESUMEN}

Se presenta un estudio de comparación, a nivel laboratorio, de dos métodos de extracción de pectina a partir de residuos de cáscara de naranja: el método por hidrólisis ácida convencional y el método de extracción por hidrólisis ácida asistida por microondas (HMO). Los tiempos requeridos para la extracción por HMO fueron considerablemente menores. Se establecen los siguientes valores óptimos para la operación de hidrólisis mediante ambos métodos, dentro de los rangos estudiados: 2,17 para el pH y 18:1 para la proporción de solvente: materia prima (mL:g). El tiempo óptimo para la extracción HMO fue $7 \mathrm{~min}$. Se ha obtenido una ecuación, que representa el desempeño de la extracción de pectina HMO con confiabilidad dentro del intervalo de valores estudiado, para estimar el porcentaje de rendimiento en función del pH, proporción solvente: materia prima y tiempo de extracción. Aplicando este método se pretende generar un ahorro de energía y tiempo en el proceso de producción de pectina.

Palabras Clave: Pectina, Microondas, Hidrólisis Ácida, Residuos de Naranja (Citrus cinensis). 